\title{
Effect of two gold compounds on lysosomes
}

\author{
PERNILLE MøLLER GRAABÆK AND SUSANNE MøLLER PEDERSEN
}

From the Institute of Cell Biology, Department of Anatomy, University of Aarhus, Aarhus; and the Department of Clinical Chemistry, Svendborg Hospital, Svendborg, Denmark

SUMMARY The effect of two gold(I) compounds on stability of lysosomes in vitro was studied. Lysosomes from homogenates of rat kidney cortex were isolated by differential centrifugation. These lysosomes were incubated at $37^{\circ} \mathrm{C}$ with widely varied concentrations of sodium aurothiomalate and sodium aurothiosulphate for 5, 35, and 65 minutes. Acid phosphatase activities were measured and used as an indication of lysosomal membrane stability in the presence and absence of drugs. The enhanced release of acid phosphatase from lysosomes by aurothiomalate and aurothiosulphate was related to dose, but the drugs differed substantially in their potencies. The disruptive effect on lysosomes was more marked for aurothiosulphate than for aurothiomalate. In addition, both drugs inhibited acid phosphatase activities at relatively high gold concentrations. Aurothiomalate had a moderate and aurothiosulphate a weaker inhibitory effect on the enzyme. Our results indicate that aurothiomalate and aurothiosulphate exert their beneficial effect in the treatment of rheumatoid arthritis through mechanism(s) other than lysosomal membrane stabilisation.

Key words: gold thiomalate, gold thiosulphate, acid phosphatase.

The effectiveness of gold compounds in the treatment of rheumatoid arthritis has stimulated interest in the mechanism by which these drugs exert their therapeutic effect.

A function which has been attributed to other anti-inflammatory drugs, steroidal and non-steroidal, is that of lysosomal membrane stabilisation. ${ }^{1-4}$ This concept implies that these drugs prevent the labilisation of lysosomes and thus inhibit the liberation of deleterious lysosomal enzymes, which are capable of degrading the various components of connective tissue. It has often been suggested that gold compounds may also act by stabilising the lysosomal membrane. The few studies taking this approach are conflicting, however. No stabilising effect of gold thiomalate and gold thioglucose on rabbit liver lysosomes $^{5}$ and of gold thiomalate on rat liver lysosomes ${ }^{2}$ in vitro was found, whereas a stabilising effect of gold thiopropanol sulphonate on rat kidney lysosomes was observed. ${ }^{6}$

It has been found that gold accumulates in the lysosomes of synovial cells ${ }^{7-9}$ and renal proximal cells ${ }^{10}$ in patients with rheumatoid arthritis during

Accepted for publication 26 November 1987.

Correspondence to Dr Pernille Møller Graabæk, Anatomisk Institut A, Aarhus Universitet, DK-8000 Aarhus C, Denmark. chrysotherapy, which makes it possible that gold compounds exert their therapeutic or toxic effects, in some way, on the lysosomes.

The aim of the present study, therefore, was to investigate the effect of various concentrations of gold on a well characterised lysosomal fraction and to compare the effect of two different gold compounds in order to elucidate the role of the ligand.

\section{Materials and methods}

\section{R U G S}

Sodium aurothiomalate was purchased from RhonePoulenc Pharma Norden, Birkerød, Denmark and sodium aurothiosulphate was obtained from Ferrosan, Søborg, Denmark. Gold stock standards of aurothiomalate and aurothiosulphate were prepared in $0.25 \mathrm{M}$ sucrose, $\mathrm{pH} 7.2$, in the concentration range $1.25-125 \mu \mathrm{g}$ gold $/ \mathrm{ml}$ and $1.25-250 \mu \mathrm{g} \mathrm{gold} / \mathrm{ml}$ respectively. The concentrations of aurothiomalate and aurothiosulphate are expressed as elementary gold throughout.

PREPARATION OF LYSOSOMAL SUSPENSION Four non-starved male Wistar rats, weighing 250-300 g, were used in each experiment. The animals were anaesthetised by intraperitoneal 
injection of sodium pentobarbital $(50 \mathrm{mg} / \mathrm{kg}$ body weight) and the kidneys perfused in situ with ice cold $0 \cdot 3 \mathrm{M}$ sucrose containing $1 \mathrm{mM}$ edetic acid, $\mathrm{pH}$ $7 \cdot 2$, for three minutes. The kidneys were removed, the renal cortexes rapidly excised, weighed, minced, and diluted 1:10 (w/v) with the ice cold solution used for perfusion. The tissue suspension was then homogenised in a Potter-Elvehjelm glass homogeniser by 10 complete strokes with a Teflon pestle rotating at about $200 \mathrm{rpm}$. Care was taken to follow the same homogenisation procedure and to use the same Teflon pestle and glass homogeniser for all experiments in order to reduce variations in the degree of lysosome disruption.

The homogenate was fractionated by the method of Maunsbach. " The light fraction and the large mitochondrial fraction were carefully removed from the materials sedimenting at $9000 \mathrm{~g}$ and the remaining pellet enriched with lysosomes (primary granule fraction) was gently rinsed and resuspended in $30 \mathrm{ml}$ ice cold $0.25 \mathrm{M}$ sucrose containing $1 \mathrm{mM}$ edetic acid,

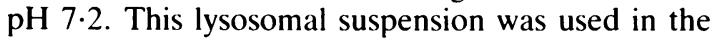
following experiments. Further purification of the lysosomes as described by Maunsbach ${ }^{11}$ (e.g., removing the last relatively small amount of mitochondria) was found to be unnecessary in this study, whereas the time saved by stopping the isolation at the stage of primary granule fraction was considered of importance.

CONTROL OF THE LYSOSOMAL FRACTION For electron microscopic analysis of the composition of the lysosomal fractions pellets enriched with lysosomes were fixed in situ in the centrifuge tube or fixed in suspensions and further prepared for electron microscopy as described by Maunsbach ${ }^{11}$ and Sjöstrand and Borgström. ${ }^{12}$ Ultrathin sections. perpendicular to the surface of the pellets and from different parts of them, were cut through their entire depth. The sections were stained with uranyl acetate and lead citrate and examined in a JEM-100B electron microscope.

Biochemical determination of total acid phosphatase activity and cytochrome oxidase (mitochondrial marker enzyme) activity in the lysosomal suspension was compared with that of the homogenate. Cytochrome oxidase activity was measured by the method of Wharton and Tzagoloff. ${ }^{13}$

\section{ASSAYS OF LYSOSOMAL MEMBRANE} S T A B I L I T Y

Labilisation or stabilisation of lysosomal membranes in the presence of gold was ascertained by comparing the release of the lysosomal marker enzyme, acid phosphatase, with that in controls. Aliquots $(3.5 \mathrm{ml})$ of the lysosomal suspension were delivered to propyethylene test tubes containing $700 \mu \mathrm{l}$ of $0.25 \mathrm{M} \stackrel{\circ}{\text { ? }}$ sucrose, $\mathrm{pH} 7 \cdot 2$, at $0-4^{\circ} \mathrm{C}$, without (controls) or with gold added. The final concentrations of gold in the lysosome-aurothiomalate suspensions were $0 \cdot 2,0 \cdot 4$, 등 $1,2,4,10,20 \mu \mathrm{g} / \mathrm{ml}$ and in the lysosome-aurothio- $\frac{\bar{\sigma}}{\bar{\omega}}$ sulphate suspensions $0 \cdot 2,0 \cdot 4,1,2,4,10,20,40 \frac{\mathrm{s}}{\mathrm{D}}$ $\mu \mathrm{g} / \mathrm{ml}$. Two samples $(0.5 \mathrm{ml})$ of each mixture were $\varrho$ preincubated at $37^{\circ} \mathrm{C}$ for exactly 5,35 , and $65 \%$ minutes, after which enzyme substrate was added $\overrightarrow{0}$ for measurement of the free acid phosphatase activity.

Samples $(0.5 \mathrm{ml})$ of controls and lysosomal suspensions containing gold were frozen (in liquid $\left.\mathrm{CO}_{2}\right)$ and thawed three times for complete disruption of the lysosomes. The samples were then preincubated for 35 minutes at $37^{\circ} \mathrm{C}$ before enzyme or substrate was added for determination of the total lysosomal acid phosphatase activity.

The samples were not centrifuged before assay of the released acid phosphatase in order to eliminate the errors due to differences in the sedimentation of $\overparen{D}$ free lysosomal enzymes or gold compounds, or $\vec{\theta}$ both, with the lysosomal membranes.

ASSAY OF ACID PHOSPHATASE

Acid phosphatase was assayed at $\mathrm{pH} 5.0$ with $\beta$-glycerophosphate as substrate. Liberated phos- $\bar{Q}$ phate was determined by the method of Lowry and $\stackrel{\circ}{\circ}$ Lopez ${ }^{14}$ using amidol as reducing agent. The specific $\varrho$ acid phosphatase activity was expressed as $\mu$ mol of $\overrightarrow{\hat{O}}$ phosphate liberated $/ 20 \mathrm{~min} / \mathrm{mg}$ protein. Protein was determined by the method of Lowry et al ${ }^{15}$ with bovine serum albumin as a standard. For reasons of comparisons the activity of acid phosphatase is expressed as percentage of control total enzyme activity.

EFFECT OFGOLD ON ACID PHOSPHATASE ACTIVITY

The effect of gold on the total acid phosphatase activity of a disrupted lysosomal suspension was studied. Aliquots $(0.4 \mathrm{ml})$ of a lysosomal suspension were transferred to: test tubes and $100 \mu \mathrm{l} 0.25 \mathrm{MN}$ sucrose, $\mathrm{pH} 7 \cdot 2$, without (controls) or with gold was added at different steps in the procedure: $(a)$ before $\mathrm{N}$ the lysosomal suspensions were frozen and thawed, $\omega$ (b) after freezing and thawing, and (c) after incuba tion for acid phosphatase before determining the을 liberated phosphate. The final gold concentrations $\overline{\mathscr{\Phi}}$ for the lysosomal suspensions incubated with ${ }^{+}$ aurothiomalate were 0.2 and $20 \mu \mathrm{g} / \mathrm{ml}$ and for ${ }^{-}$ aurothiosulphate $0 \cdot 2,20$, and $40 \mu \mathrm{g} / \mathrm{ml}$.

STATISTICAL ANALYSIS

Statistical analysis was by Student's $t$ test with significance level at $p<0 \cdot 05$. The number of experiments is indicated in the individual figures. 


\section{Results}

PROPERTIES OF THE LYSOSOMAI FRACTION When analysed by electron microscopy the lysosomal fraction contained predominantly membrane limited bodies $(0 \cdot 5-1.5 \mathrm{um}$ in diameter) with even densely stained contents. Mitochondria and some unidentified membranous structures were also present but in considerably less numbers than the lysosomes.

Biochemically. the lysosomal fraction contained about $7.5 \%$ of the acid phosphatase activity of the homogenate and the specific activity of this enzyme was eight to nine times greater than in the homogenate. In contrast. only about $0.2 \%$ of the cytochrome oxidase activity of the homogenate was present in this fraction, and it had a low specific activity. The ultrastructural and biochemical data thus demonstrate a lysosomal fraction quite rich in lysosomes. though still contaminated by other cell components.

EFFECT OF GOLD ON ACTIVITYOF ACID

PHOSPHATASEFROMRATKIDNEY

\section{LYSOSOMES}

The effect of gold on the total acid phosphatase activity of a disrupted lysosomal suspension when gold was added at different steps in the procedure as described under "Materials and methods" was studied. The results showed that aurothiomalate had a moderate and aurothiosulphate a weaker inhibitory effect on the lysosomal enzyme. Gold did not affect disruption of the lysosomes or determination of liberated phosphate.

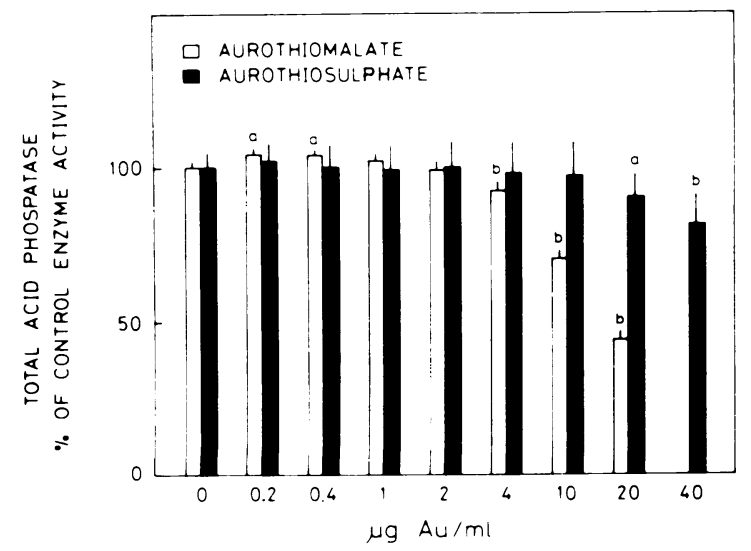

Fig. I Direct effect of aurothiomalate and aurothiosulphate on acid phosphatase from disrupted lysosomal suspensions. Each value represents the mean (SD) of the total activity of acid phosphatase in the lysosomal suspensions used in the experiments shown in Figs 2 and 3. "Significant at $p<0.055 \cdot$ control: "significant at $p<0 \cdot 01$ i control.
Owing to the direct inhibitory effect of gold on lysosomal acid phosphatase it was found necessary to determine the total acid phosphatase activity in all lysosomal suspensions. Fig. 1 shows the effect of various concentrations of aurothiomalate and aurothiosulphate on lysosomal acid phosphatase. Acid phosphatase activity was reduced by $8 \%$. $30 \%$. and $66 \%$ when preincubated with aurothiomalate at $4 \cdot 0.10$. and $20 \mathrm{um} / \mathrm{ml}$ respectively. A much weaker

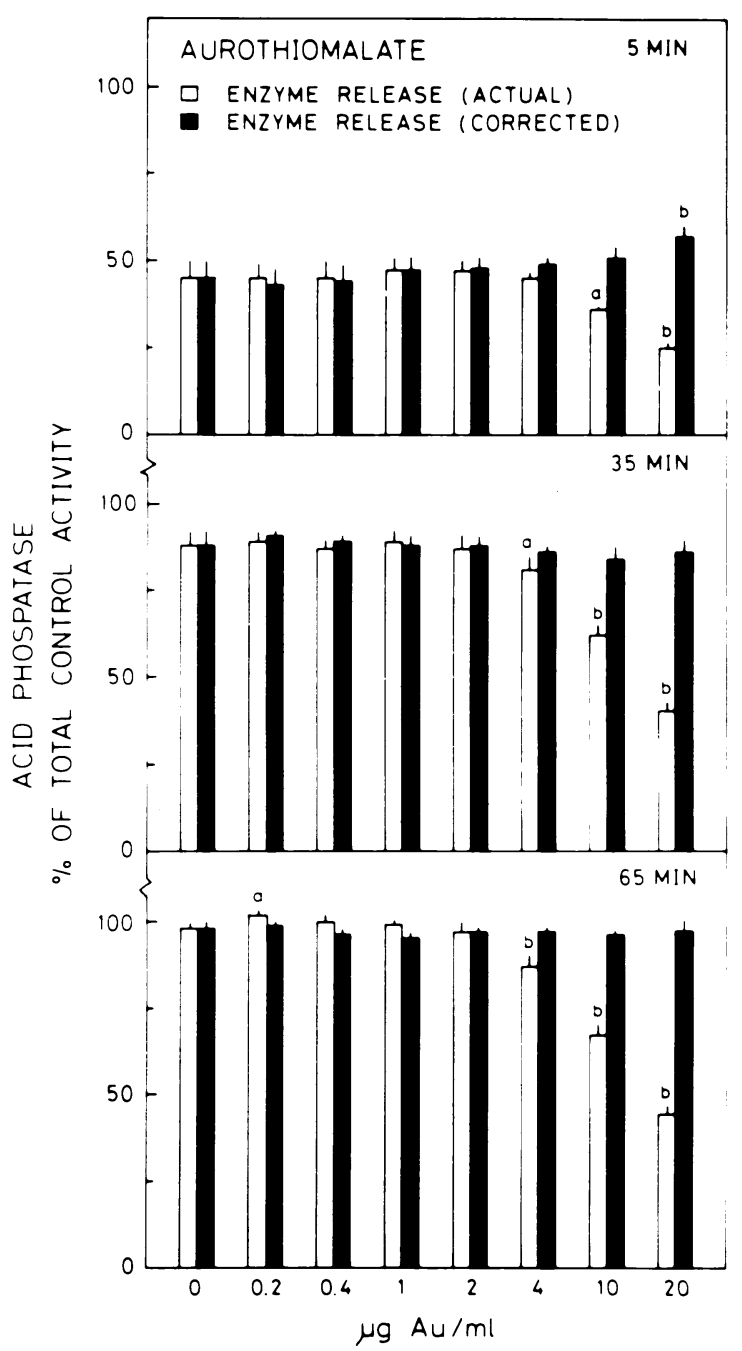

Fig. 2 Effect of aurothiomalate on the release of acid phosphatase from rat kidney lysosomes. Lisosomes were preincubated at $37^{\circ} \mathrm{C}$ with aturothiomalate' at the concentrations and for the time periods indicated. Each lalue represents the mean (SD) of three separate experiments. "Significant at $p<0) \cdot(15)$ 1 control: "significant at $p<0.01$ 1 control. Fig. I shows the values used for correction of enzlime release. 
inhibitory effect of aurothiosulphate on acid phosphatase activity was observed-namely, $10 \%$ at 20 $\mu \mathrm{g} / \mathrm{ml}$ and $19 \%$ at $40 \mu \mathrm{g} / \mathrm{ml}$.

\section{EFFECT OF GOLD(I) COMPOLNDSON STABILITY OF I.YSOSOMES FROM RAT KIDNEY}

Figs 2 and 3 illustrate the effect of aurothiomalate and aurothiosulphate on the release of acid phosphatase from rat kidney lysosomes. It was found that gold had a dose dependent labilisation effect on the lysosomal membrane and this effect was more marked for aurothiosulphate than for aurothiomalate.

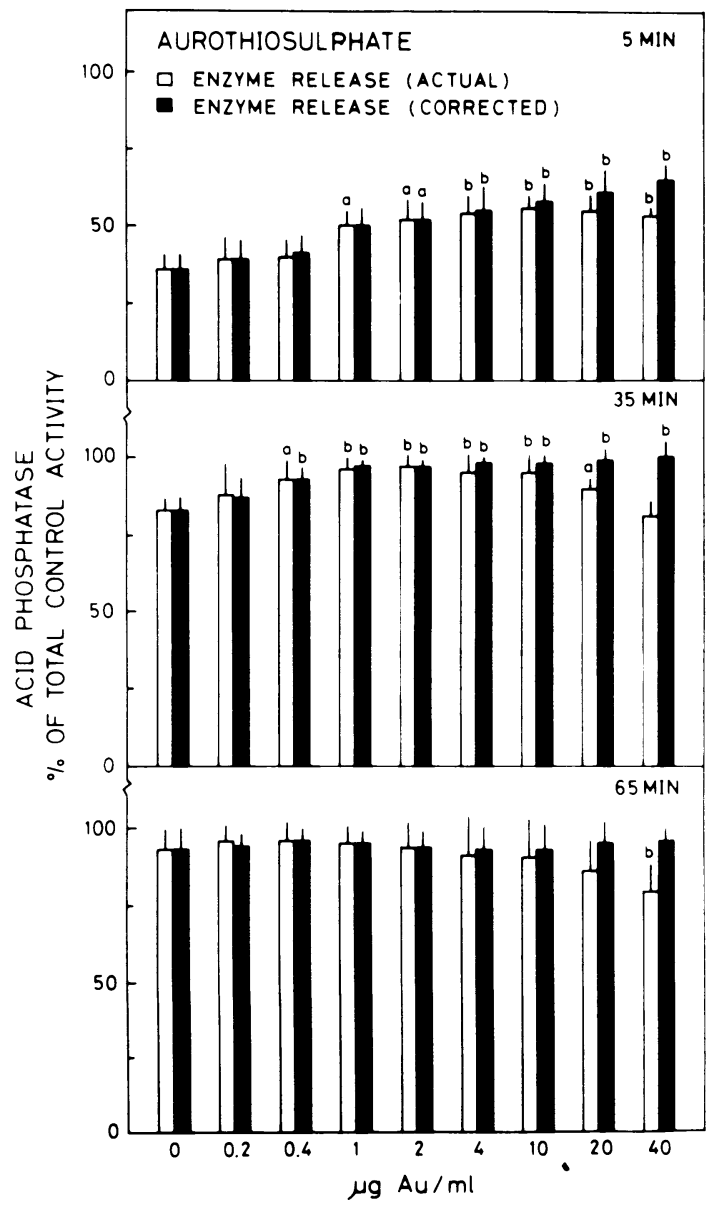

Fig. 3 Effect of aurothiosulphate on the release of acid phosphatase from rat kidney lysosomes. Lysosomes were preincubated at $37^{\circ} \mathrm{C}$ with aurothiosulphate at the concentrations and for the time periods indicated. Each value represents the mean $(S D)$ of four separate experiments. "Significant at $p<0.05 \mathrm{v}$ control: " significant at $p<0.01 v$ control. Fig. I shows the values used for correction of enzyme release.
Aurothiomalate

When intact lysosomes were preincubated at $37^{\circ} \mathrm{C}$ for 5.35 , and $65 \mathrm{~min}$ with aurothiomalate io? concentrations ranging from $0 \cdot 2$ to $20 \mu \mathrm{g} / \mathrm{ml}$ the lysosomal enzyme activity was found to decrease gradually with concentrations $\geqslant 10 \mu \mathrm{g} / \mathrm{ml}$ (Fig. 2) $\underset{\vec{\nabla}}{\overrightarrow{0}}$ This may be thought to indicate a stabilising effect of aurothiomalate on the lysosomes at high golds concentrations. This apparent stabilisation effect o $\overrightarrow{5}$ aurothiomalate on the lysosomal membrane however. could be accounted for entirely by a directw inhibitory effect upon the enzyme activity. Thu corrected for the observed inhibitory effect upon thẹ acid phosphatase activity, the results for fivet minutes of preincubation showed a gradual labilisatiois effect of aurothiomalate at concentrations $\geqslant 1$. (g $\mu \mathrm{g} / \mathrm{ml}$. It appeared. however, that the enzyme was slightly activated at small concentrations of aurothiomalate (Fig. 1). When corrected for this effect the release of acid phosphatase fell below the control value. indicating a weak lysosomal memo brane stabilising effect (Fig. 2). No statisticall $\vec{x}$ significant effect of aurothiomalate on the lysosomabo membrane could be shown at the 35 and 65 minutio time intervals.

\section{Aurothiosulphate}

When lysosomes were preincubated with auro을 thiosulphate at $37^{\circ} \mathrm{C}$ for five minutes the release of acid phosphatase was increased in the concentratior? range tested, reaching a maximum at $10 \mu \mathrm{g} / \mathrm{ml}$ (Fig $3)$. When corrected for the observed direct inhibiz tory effect of aurothiosulphate on acid phosphatase activity a gradual labilisation effect of the drug ove $\bar{z}$ the entire concentration range $(0 \cdot 2-40 \mu \mathrm{g} / \mathrm{ml})$ was observed. A dose related effect could also be show 7 . after the 35 minute period, whereas no effect of the drug could be demonstrated after 65 minute (Fig. 3).

\section{Discussion}

A well defined lysosomal fraction from rat kidne? cortex was incubated at $37^{\circ} \mathrm{C}$ in the presence of widely varied concentrations of aurothiomalate and aurothiosulphate. The chosen concentration range of gold included the therapeutic levels $(0 \cdot 3-5 \mu \mathrm{g} / \mathrm{ml}$ achieved in clinical use of these compounds. ${ }^{16}$ i The present study showed that the two gold com? pounds enhanced the release of lysosomal markero enzyme in a dose related fashion, and that the differ in their potencies. At a concentration of $20 \mu \Phi$ gold $/ \mathrm{ml}$ aurothiomalate and aurothiosulphate en $\Phi_{\Omega}$ hanced the release of acid phosphatase by $10 \%$ an $20 \%$ respectively, indicating that aurothiosulphate possesses a stronger labilising effect on lysosomas 
membranes than aurothiomalate. In addition, the two drugs had a direct inhibitory effect on acid phosphatase, with aurothiomalate being the most potent inhibitor. Aurothiomalate showed $55 \%$ and aurothiosulphate $10 \%$ inhibition of enzyme activities at $20 \mu \mathrm{g} \mathrm{gold} / \mathrm{ml}$. The present data demonstrate that it is important to correct for the interference of gold with enzyme activities to obtain a valid interpretation of the experimental results.

The present labilising effect of high concentrations of gold on isolated lysosomes has never been described before. In the few previous studies on the effect of gold on the stability of lysosomal membranes in vitro no effect of aurothiomalate was found. ${ }^{25}$ Our findings are in general agreement with the observations that aurothiomalate ${ }^{18}$ and aurothiosulphate $^{19}$ at low concentrations do not affect the release of lysosomal enzymes from polymorphonuclear leucocytes, whereas aurothiosulphate ${ }^{19}$ at higher concentrations shows a slight inhibitory effect. As the authors ${ }^{19}$ did not investigate the direct effect of gold on the activities of lysosomal marker enzymes it is impossible to decide whether the inhibitory effect observed is due to a stabilising effect of gold on the lysosomal membrane or simply due to an inhibitor effect on the activities of the lysosomal enzymes as happened to be the case in our study.

The different ability of the two gold compounds to labilise the lysosomal membranes and to inhibit the activity of acid phosphatase strongly suggests that the interaction of gold with lysosomes is affected by the ligand. This idea is supported by the findings that auranofin shows a potent inhibitory effect, ${ }^{19}$ whereas aurothioglucose even at high concentrations shows no inhibitory effect on the release of lysosomal enzymes from polymorphonuclear leucocytes, ${ }^{50}$ and by the findings that different antiarthritic gold preparations differ markedly in their ability to inhibit the activity of lysosomal enzymes. $^{21}$

Although the present study cannot explain how the two gold compounds exert their labilising effect on in vitro lysosomes, one or more of the following possibilities shoult be considered: $(a)$ the gold compounds may interact with the outer or inner surface of the lipoprotein-membrane structure and thereby change the integrity of the lysosomal membrane, resulting in an enhanced release of acid phosphatase; $(b)$ the gold compounds may accumulate within lysosomes by a concentration dependent mechanism or a proton pump dependent mechanism, or a combination of both, as described for weak base amines. ${ }^{22}$ The accumulation of drugs could lead to osmotic swelling and even disruption of lysosomes with release of acid phosphatase; and (c) the gold compounds may inhibit lysosomal phospholipases and thereby decrease the transport of amino acid hydrolysis products out of the lysosomes. ${ }^{23}$ Accumulation of hydrolysis products could lead to osmotic swelling and eventually disruption of the lysosomes, resulting in enhanced release of acid phosphatase. This mechanism of phospholipase inhibition has been described for various cationic drugs and for other metal ions. ${ }^{24}$

A possible mechanism of action in vivo consistent with the present findings is that aurothiomalate and aurothiosulphate, which are anionic compounds, bind protons in the acidic interior of lysosomes. This would raise the intralysosomal $\mathrm{pH}$ and thereby neutralise the lysosomal enzymes, which if released could perpetuate the inflammatory process. In addition, it is probable that the gold compounds affect lysosomal function or intracellular processes, or both, by a direct inhibitory effect on lysosomal enzymes as suggested by Persellin and Ziff, ${ }^{25}$ Ennis et $a l^{5}$ and Ghadially et $a .^{7}$ This hypothesis is in accordance with our findings and the findings of others $^{521} 25$ that gold at high concentrations has a direct inhibitory effect on lysosomal enzymes. Owing to the high concentrations of gold required to produce significant inhibition of lysosomal enzymes it is unlikely that gold exerts an extracellular effect on lysosomal enzymes in vivo. High gold concentrations within lysosomes could, however, readily be attained. It has been found that synovial cells after chrysotherapy show large lysosomal bodies (aurosomes) containing numerous lipid droplets, ${ }^{7}$ myelin structures, ${ }^{26}$ and gold deposits, which provides further supportive evidence for the intralysosomal action of gold compounds on catabolic enzymes.

In summary, aurothiomalate and aurothiosulphate have been shown to labilise lysosomal membranes at relatively high gold concentrations, and, in addition, it was found that the drugs exert a direct inhibitory effect on acid phosphatase-the lysosomal marker enzyme. Although it is not possible to determine directly from these in vitro experiments what the in vivo effects of gold compounds may be, our results do not support the idea that gold compounds exert their beneficial effects by stabilising the lysosomal membranes. It appears more likely that these drugs act by inactivation of lysosomal enzymes by inducing a raised intralysosomal $\mathrm{pH}$ or by a direct inhibitory effect on lysosomal enzymes, or both. The differences observed in the effects of the two gold compounds on lysosomal membranes and lysosomal acid phosphatase suggest that their individual ability to interact with the lysosomal system is affected by the ligand.

The authors are indebted to Mrs Hanne Weiling for excellent technical assistance. 


\section{References}

1 Weismann G. Thomas L. Studies on lysosomes. II. The effect of cortisone on the release of acid hydrolases from a large granule fraction of rabbit liver induced by an excess of vitamin $A$. J Clin Invest 1963; 42: 661-9.

2 Ignarro L J. Effects of anti-inflammatory drugs on the stability of rat liver lysosomes in vitro. Biochem Pharmacol 1971: 20: $2847-60$.

3 Smith J R, Sabin C. Gilchrest H, Williams S. Effect of antiinflammatory drugs on lysosomes and lysosomal enzymes from rat liver. Biochem Pharmacol 1976: 25: 2171-7.

4 Heiman A S. Lee H J. Stabilisation of rat liver lysosomes by new anti-inflammatory steroids in vitro. Steroids 1981; 33: 365-73.

5 Ennis R S. Granda J L. Posner A S. Effect of gold salts and other drugs on the release and activity of lysosomal hydrolases. Arthritis Rheum 1968; 11: 756-64.

6 Rodrigues L E. Galle P. Lysosomotropisme et action antiinflammatoire des sels d'or. Rev Rhum Mal Osteoartic 1985; 52 : 479-83.

7 Ghadially F N. Oryschack A F. Mitchell D M. Ultrastructural changes produced in rheumatoid synovial membrane by chrysotherapy. Ann Rheum Dis 1976; 35: 67-72.

8 Nakamura H, Igarashi M. Localisation of gold in synovial membrane of rheumatoid arthritis treated with sodium aurothiomalate. Ann Rheum Dis 1977: 36: 209-15.

9 Vernon-Roberts B. Doré J L. Jessop J D. Henderson W J. Selective concentration and localization of gold in macrophages of synovial and other tissues during and after chrysotherapy in rheumatoid patients. Ann Rheum Dis 1976; 35: 477-86.

10 Strunk S W. Ziff M. Ultrastructural studies of the passage of gold thiomalate across the renal glomerular capillary wall. Arthritis Rheum 1970; 13: 39-52.

11 Maunsbach A B. Isolation and purification of acid phosphatasecontaining autofluorescent granules from homogenates of rat kidney cortex. J Ultrastruct Res 1966: 16: 13-34.

12 Sjöstrand F S. Borgström B. The lipid components of the smooth-surfaced membrane-bounded vesicles of the columnar cells of the rat intestinal epithelium during fat absorption. $J$ Ultrastruct Res 1967: 20: 140-60.
13 Wharton D C. Tzagoloff A. Cytochrome oxidase from beef. heart mitochondria. Methods Enzymol 1967; 10: 245-50.

14 Lowry $\mathrm{O} \mathrm{H}$, Lopez J A. The determination of inorganic phosphate in the presence of labile phosphate esters. $J$ Bioto Chem 1946; 162: 421-8.

15 Lowry O H. Rosebrough N J. Farr A L, Randall R J. Protein measurement with the folin phenol reagent. J Biol Chem 1951: 193: $265-75$.

16 Lorber A. Monitoring gold plasma levels in rheumatoide arthritis. Clin Pharmacokinet 1977; 2: 127-46.

17 Pedersen S M. Graabæk P M. Gold in erythrocytes, whole $\overrightarrow{0}$ blood. and plasma during long-term chrysotherapy. Ann RheumDis 1980; 39: 576-9.

18 Carevic O. Effects of D-penicillamine, dichlofenac sodium and gold sodium thiomalate upon the selective release of lysosoma enzymes from human polymorphonuclear leucocytes to immunce complex. Agents Actions 1985: 16: 407-10.

19 Finkelstein A E, Roisman F R. Ladizesky M G. Walz D T. Auranofin and lysosomal enzymes. J Rheumatol 1982; 9(supplé $8)$ : 46-53.

20 Wildfeuer A. Effect of anti-rheumatic drugs on the release of lysosomal enzymes from human leucocytes. Z Rheumatol $1984 ;$ 43: 23-6.

21 Burkhardt D. Stephens R W. Ghosh P, Taylor T K F. Inhibition of synovial fluid lysosomal glycosidases by antiarthritic gold preparations. Agents Actions 1978; 8: 251-7.

22 Seglen P O. Inhibitors of lysosomal function. Methods Enzymole 1983; 96: 737-64.

23 Lucy J A. Lysosomal membranes. In: Dingle J T. Fell H B, eds Lysosomes in biology and pathology. Vol 2. Amsterdam: North-Holland. 1969: 313-41.

24 Powell J H, Reidenberg M M. Further studies of the response of kidney lysosomes to aminoglycosides and other cations. Biochem Pharmacol 1983; 32: 3213-20.

25 Persellin R H. Ziff $M$. The effect of gold salt on lysosomalo enzymes of the peritoneal macrophage. Arthritis Rheum $1966 ; \overrightarrow{\bar{B}}$ 9: 57-65.

26 Barland P. Novikoff A B. Hamerman D. Fine structure and cytochemistry of rheumatoid synovial membrane with special reference to lysosomes. Am J Pathol 1964; 44: 853-66. 